\title{
Crossed aphasia. I: A case-study with purely deep lesion
}

\author{
M. Laiacona, C. Stangalino and L. Lorenzi \\ Neuropsychology Unit, Neurology Department, Salvatore Maugeri Clinica del Lavoro \\ Foundation, Medical Centre of Rehabilitation, Veruno (NO), Italy
}

Correspondence to: Dr M. Laiacona, Servizio di Neuropsicologia della Fondazione S. Maugeri

Clinica del Lavoro, Istituto di Ricovero e Cura a Carattere Scientifico, Centro Medico di

Riabilitazione di Veruno (NO), Italy

\begin{abstract}
In this paper, we describe the case of a right-handed man, MR, who after right thalamic haemorrhage presented subtranscortical aphasia. Of the disturbances generally associated with standard left hemisphere functions, the patient presented acalculia but not apraxia. Among the functions attributed to the standard right hemisphere, MR showed impairment in affective language and presented unilateral neglect and a strong position preference.
\end{abstract}

Keywords: Aphasia - Deep lesions - Hemispheric specialisation

\section{INTRODUCTION}

The prevalence of crossed aphasia ranges from 0.38 to $10 \%$ (Branch et al., 1965; Hécaen et al., 1971; Gloning, 1977; Zangwill, 1979).

The investigation of this syndrome together with the analysis of reversed lateralisation of right hemisphere functions (Fisher et al., 1991) may provide further insight into hemispheric specialisation and the intrahemispheric organisation of cognitive functions. The aim of this study was to investigate whether in our patient all neuropsychological functions were cross-localised, or whether there was an associated deficit of functions generally subserved by either the left or right hemisphere.

\section{PATIENT}

MR, a 68-year-old retired house-painter with 5 years of schooling, suffered a stroke with left hemiplegia and global aphasia on September 7, 1990. A CT-scan revealed an intracerebral haematoma affecting right deep structures. By November 30, 1990, his aphasic deficits had cleared to some extent but were still present and in December he was admitted to our Medical Centre for rehabilitation. The neurological examination performed at that time showed a severe left-sided motor and somato-sensory impairment, and left extinction of visual stimuli, besides missing two out of ten single stimuli on each left quadrant.
Tendon reflexes were brisk, and an extensor plantar response was present on the left side. MR did not present anosognosia.

Handedness was assessed by means of the Edinburgh Inventory (Oldfield, 1971) and an enquiry designed for the Italian population (Salmaso and Longoni, 1985). He was 100\% right-handed on both questionnaires and there was no family history of lefthandedness.

\section{NEURORADIOLOGICAL EXAMINATION}

The NMR examination performed in March 1991 confirmed the right deep lesion involving the genu and the posterior limb of the internal capsule, the lateral and posterior parts of the thalamus, extending to cerebral peduncle, optic tract and putamen. The assial and coronal slices showing the lesion plus their representation on schematic diagrams are displayed in Fig. 1.

Regional cerebral blood flow was assessed by SPECT using a rotating gamma camera. A complete set of tomographic slices, $1.4 \mathrm{~cm}$ thick, was reconstructed. This examination, performed on February 4, 1991, revealed right cortical temporalparietal-occipital hypoperfusion and hypoperfusion of the ipsilateral deep nuclei (Fig. 2). 


\section{NEUROPSYCHOLOGICAL EXAMINATION}

MR was given a wide range of standardised tests, and some ad hoc tests for which standardisation was unavailable, to assess left and right hemispheric functions, memory and other less strictly lateralised functions. Whenever possible, scores on the standardised tests were adjusted for age and education and judged against the threshold of the lower $5 \%$ of the normal population (Capitani and Laiacona, 1988).

Table I reports MR's performance on a set of standardised tests. Some findings will be commented upon here.

\section{Predominantly left hemispheric functions}

Language. MR was able to converse about familiar topics when coaxed by the examiner. He did not use verbs in infinitive form, nor did he selectively omit function words and suffixes, however, he produced sentences of one or two words, often incomplete and interrupted, and rate of speech was slow (on the average 28 words/min). Ecolalia, automatic utterances, severe word-finding difficulties, verbal and semantic paraphasias and some phonemic neologisms were also present on naming and on spontaneous speech. Some examples are reported in Appendix A. Reduced verbal output is one of the basic symptoms associated with thalamic lesions (Puel et al., 1992), and the aphasic profile of MR was not different from that expected after left thalamic damage in standard patients. Démonet et al. (1992) used the term "subtranscortical aphasia" to define some of the clinical features observed in $77 \%$ of patients with left thalamic lesions in their series of subcortical cases. This syndrome includes reduced spontaneous speech,

TABLE I. MR's performances on standardised tests

\section{Predominantly left hemisphere functions}

Language: Mild transcortical aphasia, with a greater impairment of written language.

Number processing

Acalculia test (Basso and Capitani, 1979): 7/101 (cut-off 74).

\section{Gestures}

Oral Apraxia test (De Renzi et al. 1966; Spinnler and Tognoni, 1987): 18/20 (cut-off 17).

Ideomotor Apraxia test (De Renzi et al. 1980, 1982): 70/72 (cut-off 53)

Apraxia of use (De Renzi et al. 1968): 10/14 (cut-off 14).

Predominantly right hemisphere functions

\section{Spatial cognition}

Geographical orientation (Spinnler and Tognoni, 1987): 7.5/15 (cut-off 7.25).

\section{Perceptual ability}

Judgment of Line Orientation, Form H (Benton et al., 1983): 19/30 (cut-off 16).

Segment discrimination (Spinnler and Tognoni, 1987): 24/32 (cut-off 17).

Visual form discrimination* (Benton et al., 1983): 17/32, at the vertical form 28/32 (cut-off 22).

Tactile form perception (Benton et al. 1983): 7/10 (cut-off 5).

Facial recognition* (Benton et al., 1983): 28/54, at the vertical form: $40 / 54$ (cut-off 37).

(*The multiple choice sheet was presented both as a horizontal (standard version) and a vertical form).

Unilateral Neglect and Position Preference: yes, see text

\section{Memory Tasks}

Digit span (Orsini et al., 1987): 2.5 (cut-off 3.5)

Spatial span (Orsini et al., 1987): 3.25 (cut-off 3.5)

Verbal learning (Novelli et al., 1986): $3 / 30$ (cut-off 6.5)

Spatial Learning Corsi's block-tapping test: 2.79/29.16 (on the basis of his spatial span, cut off is 4.5, Capitani et al., 1991).

Symbol-digit paired associated learning: 26 (mean score of low-educated controls 17.11, S.D. 7.76)

Other functions

Attention

Digit cancellation test (Spinnler and Tognoni, 1987): 8.5/60 (cut-off 31).

Nonverbal intelligence

Raven's progressive matrices (Spinnler and Tognoni, 1987): 18/48 (cut-off 15).

Visuo-constructional tasks

Constructional Apraxia (Spinnler and Tognoni, 1987): 8/14 (cut-off 8).

Figure recomposition from fragments (Spinnler and Tognoni, 1987) 7/14 (cut-off 3.25).

Affective language: Global aprosodia 
DEEP CROSSED APHASIA I
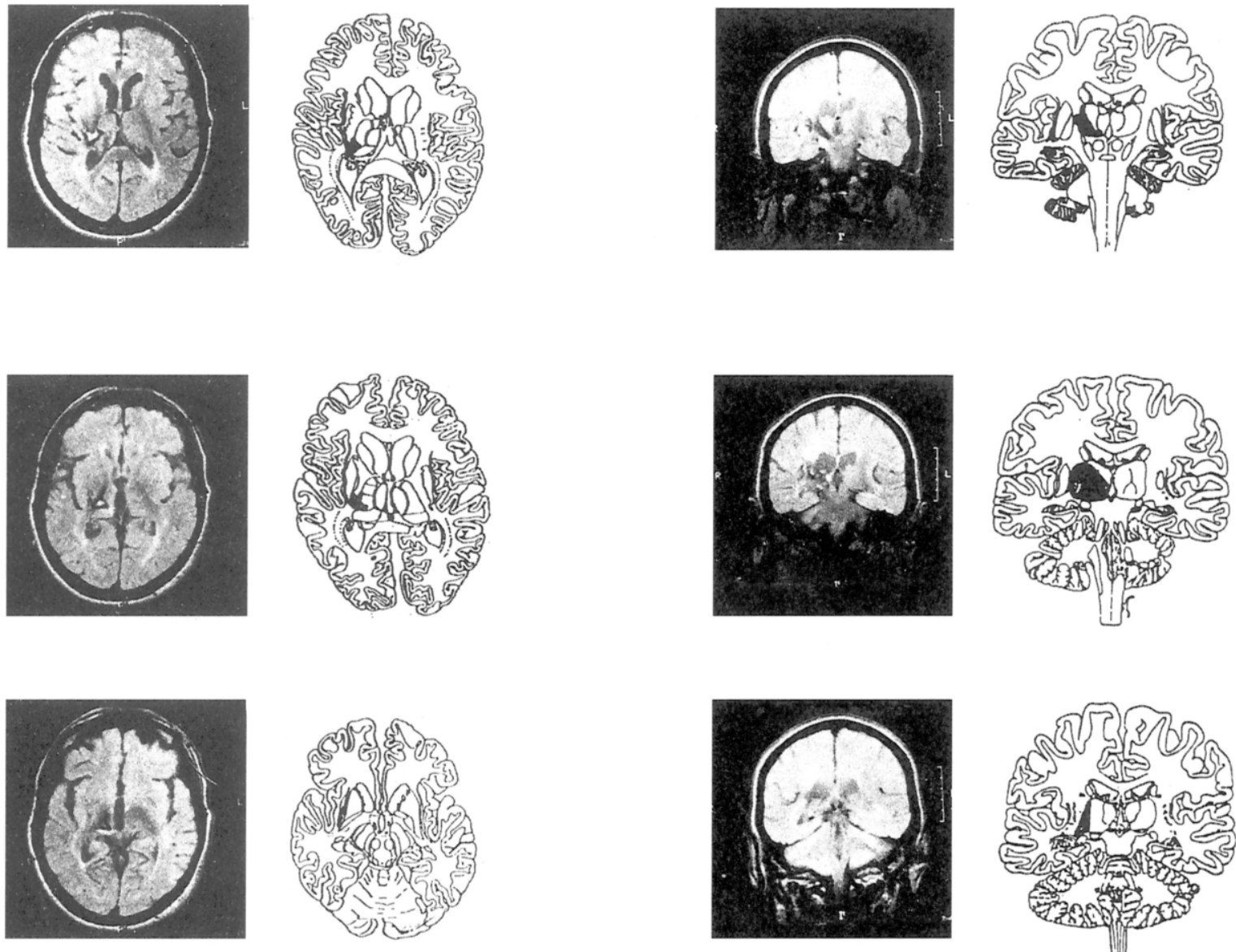

FIG. 1. NMR images with their schematic representation.

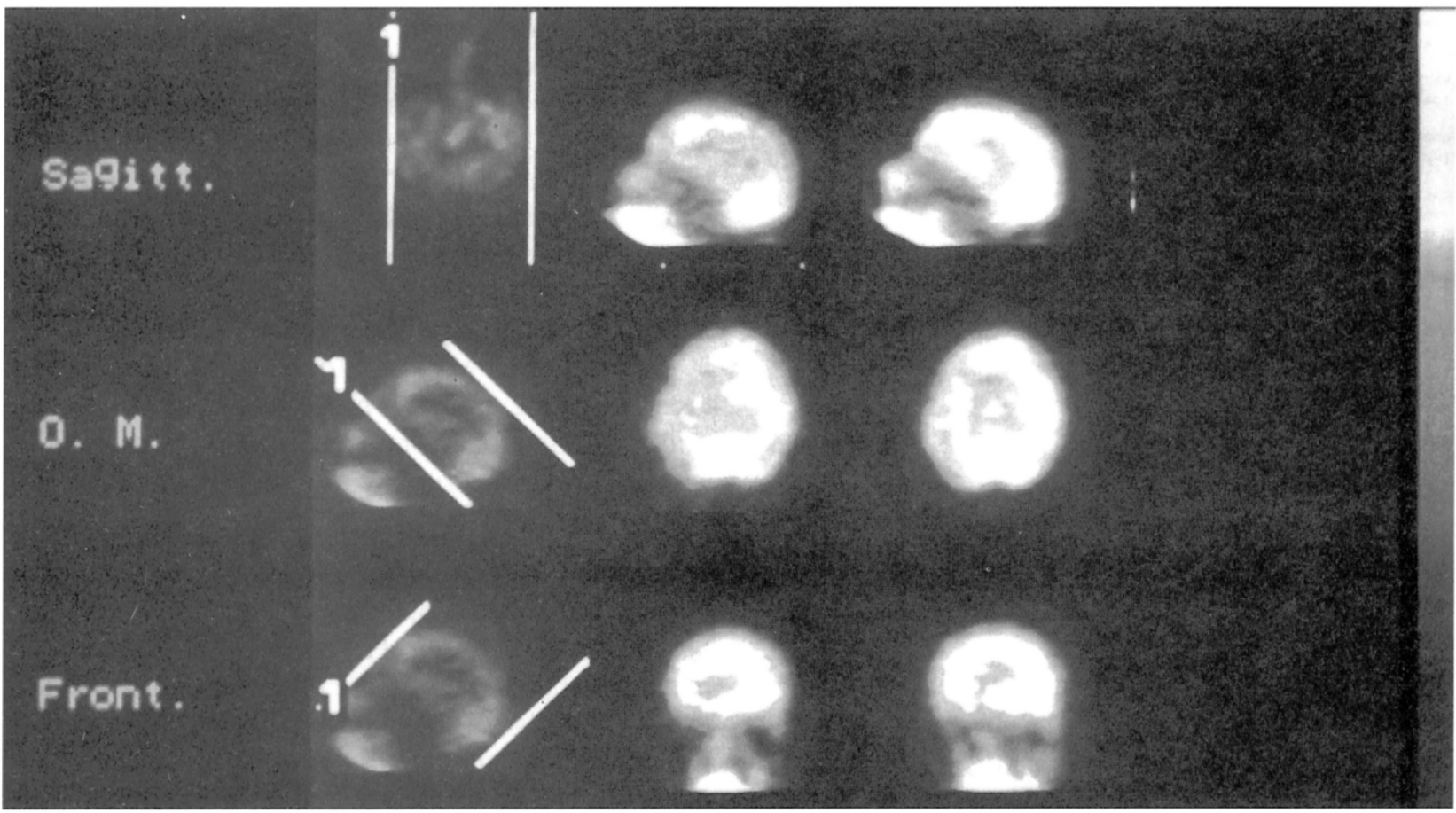

FIG. 2. SPECT study. Severe cortical and subcortical hypoperfusion in the right hemisphere is evident. 
verbal paraphasias and perseverations, frequent preservation of oral comprehension and normal word repetition. Normal repetition accounts for the term "transcortical" already used by several authors (e.g. Cappa and Vignolo, 1979). Our patient's spontaneous speech was reduced. On the Aachener Aphasia test (AAT) (Luzzatti et al. 1991), confrontation naming (score $=50 / 120)$ disclosed errors of a primarily semantic nature. Comprehension (Token Test) was moderately impaired (correct answers $=24 / 50$ ): in the first two sections MR made only two errors, whereas in the last three sections errors were, respectively, 7, 9 and 8 . Repetition (overall score of 118/150)

\begin{tabular}{|c|c|c|c|}
\hline STIMULUS & $\begin{array}{l}\text { ORAL } \\
\text { NAMIMG }\end{array}$ & $\begin{array}{l}\text { WRITTEN } \\
\text { NAMING }\end{array}$ & \\
\hline $\begin{array}{l}\text { TAvolo } \\
\text { (table) }\end{array}$ & + & aolo & (LP) \\
\hline $\begin{array}{l}\text { OKBRELLOO } \\
\text { (umbredja) }\end{array}$ & + & loleto & (NW) \\
\hline $\begin{array}{l}\text { LUMPNDX } \\
\text { (12amp) }\end{array}$ & $\begin{array}{l}\text { 2ampione } \\
\text { (SP: }\end{array}$ & no xaeponee & \\
\hline $\begin{array}{l}\text { AUTOKOBXIX } \\
\text { (cax) }\end{array}$ & + & una & + \\
\hline $\begin{array}{l}\text { Cruigcir } \\
\text { (cherriea) }\end{array}$ & $\begin{array}{l}\text { ciole } \\
\text { (NN) }\end{array}$ & no reeponse & \\
\hline $\begin{array}{l}\text { LUCERTOLA } \\
\text { (1izard) }\end{array}$ & ${ }_{\text {(Sp: enail) }}^{\text {Iumece, }}+$ & enaoma & (NW) \\
\hline $\begin{array}{l}\text { TNMsURo } \\
\text { (drum) }\end{array}$ & no reuponse & un taduro & $(N W)$ \\
\hline $\begin{array}{l}\text { occhinit } \\
\text { (gla.s.e.) }\end{array}$ & no response: & weace & (Wr) \\
\hline $\begin{array}{l}\text { VENTAGLIO } \\
(\text { fan })\end{array}$ & $\begin{array}{l}\text { fenna } \\
(\mathrm{NW})\end{array}$ & no response & \\
\hline $\begin{array}{l}\text { pixtors } \\
\text { (painter) }\end{array}$ & no reuponse. & no response & \\
\hline $\begin{array}{l}\text { OROLOCIO } \\
\text { (wristwatch) }\end{array}$ & + & lararalo & (Nw) \\
\hline $\begin{array}{l}\text { variais } \\
\text { (euiteasen) }\end{array}$ & $\begin{array}{c}\text { secchio } \\
\text { (SP: peil) }\end{array}$ & cara & (Nw) \\
\hline $\begin{array}{l}\text { LETTERA } \\
\text { (1etter) }\end{array}$ & $\begin{array}{l}\text { bollo } \\
\text { (SP1 }\end{array}$ & facoralo & (Nw) \\
\hline $\begin{array}{l}\text { BILANCIA } \\
\text { (balance) }\end{array}$ & no reuponese & bilaca & (Nv) \\
\hline $\begin{array}{l}\text { Casa } \\
\text { (house) }\end{array}$ & + & lacola & $(\mathrm{Nr})$ \\
\hline $\begin{array}{l}\text { PEscr } \\
\text { (fluh) }\end{array}$ & + & cope & (NW \\
\hline $\begin{array}{l}\text { IELERoNo } \\
\text { (telephone) }\end{array}$ & no responate & no respones & \\
\hline $\begin{array}{l}\text { STurx } \\
\text { (Atove) }\end{array}$ & + & $\begin{array}{r}\text { Mapa } \\
\text { t }\end{array}$ & (sw) \\
\hline $\begin{array}{l}\text { RONDINI } \\
\text { (Nwal Lowe) }\end{array}$ & + & tua bom & (Nw) \\
\hline $\begin{array}{l}\text { BICCRIERE } \\
\text { (g1ase) }\end{array}$ & + & cale & (Nw) \\
\hline $\begin{array}{l}+ \\
+ \text { correct reuponas } \\
{ }_{N w} \text { non word }\end{array}$ & SP & $\begin{array}{l}\text { Ele paraphasele } \\
\text { iral paragraphi. }\end{array}$ & \\
\hline
\end{tabular}

FIG. 3. Oral and written confrontation naming. was one of his less impaired language skills. Considering simple sounds and words, MR scored $58 / 60$, and his errors were due to the repetition of foreign words, compound-names and sentences. Reading aloud was limited to isolated words, and was affected by spatial exploration problems. On AAT stimuli he scored 14 out of a maximum of 30 points. This aphasic pattern points to a clinical diagnosis of subtranscortical aphasia.

Oral naming was better than written naming. Performances were also qualitatively different: oral confrontation naming revealed only semantic errors and anomias, whereas in written confrontation naming, words were misspelled and often appeared as non-words. MR never showed any attempts to selfcorrect his performance. No spatial misplacement or deletion of the left side of any words was evident (Fig. 3). A quantitative and qualitative dissociation between oral and written production has already been reported by Pillon et al. (1979), and Joanette et al. (1982) in their reviews of the literature on crossed aphasia and by Basso et al. (1985). MR's oral language was mainly impaired at the lexical level, whereas his written language was also affected at the graphemic level.

Number processing and calculation. MR failed on a written calculation test. He showed perseverations, failed to use appropriate signs, numbers and operations, and made writing and calculation errors: the score of 7 out of a top of 101 clearly falls within the pathological range. His ability to read aloud 17 numbers of one or two digits was excellent, but he read only one out of 19 numbers of three to five digits correctly. The patient's errors were characterised as decomposition (e.g. " 252 " and " 1 " for 2521) or hierarchic errors (e.g. "712" for 7012). His production of Arabic numbers to dictation (22 correct answers out of 30) was also impaired. All but one of his errors were hierarachic (e.g. "815" instead of 8015).

In conclusion MR performed poorly on several tasks involving number processing and arithmetic skills: arithmetic errors were primarily associated with the syntactic structure of numbers.

Gestures. Only a mild apraxia of use was evident; when asked to demonstrate the use of seven common objects, MR failed to demonstrate the use of a toothbrush and of a match. He correctly performed the movements linked to the use of a toothbrush, but not in the right place (brushing near the table instead of the mouth) and though he was able to put out a candle correctly, he wanted to relight it by pressing his fingers on the table. 


\section{Predominantly right hemispheric functions Spatial cognition and perceptual ability}

The patient's scores fell below the cut-off on only two out of six tests (Visual Form Discrimination and Facial Recognition). However, his performance was within normal limits when presented with vertically arranged versions of the previously failed tests. We are inclined to attribute this defective performance to neglect, a deficit distinct from other stages of spatial and perceptual cognition that were probably within the normal range.

\section{Unilateral neglect assessment}

Visual and tactile exploration. In the crossing out test eight short lines to cross out are drawn on the left and on the right of a central column in which there are only four lines (range 0-20); this task was presented three times. Overall MR missed out one line on the lower far left corner. During all three trials he processed the sheet of paper by starting from the right, and this is not the usual scanning procedure adopted in our country for reading or, one can suppose, scanning lines. In the tactile exploration task the blindfolded patient was presented with a rectangular cardboard display of 50 small wells each containing one walnut (range 0-50). The patient succeeded in lifting out all the walnuts but, once again, his search began from the upper right-hand corner of the board, moving to the left; then, once the left limit was reached, downwards and across to the right side, again following an anticlockwise path.

Line bisection. MR was presented with nine lines of different length (from 40 to $280 \mathrm{~mm}$ ) centred on a sheet of paper and was asked to indicate the midpoint. Each line was presented five times in random order to a total of 45 trials. In every trial a marked and consistent rightward displacement of the centre of each line was evident. Mean displacement was $6.0 \mathrm{~mm}$ (S.D. $4.7 \mathrm{~mm}$ ), ranging from 0.4 to 9.6 for shortest and longest lines respectively. Like normal controls (Manning et al. 1990), MR displayed a positive relationship between line length and mean deviations from the real centre $[\mathrm{F}(1,7)=17.345, p<0.005]$ as well as a linear relationship between the line length and the variability of his bisections $[F(1,7)=19.054$, $p<0.005]$. This rightward bias might reflect the adoption of a right-to-left scantrack that terminates when the point of subjective equality between the two halves of the line is reached, with systematic "undershoot" errors (Manning et al., 1990).

Drawing from memory. MR was asked to draw a flower and a face, and to put the numbers onto schematic clock-face in their correct positions. No differences between the left and right-sided details of MR's drawing of a flower and a face were evident, but he consistently failed to put the numbers onto the left side of the clock-face (Fig. 4). In two instances we also observed a top-bottom inversion and in one an anticlockwise sequence of digits.

We then investigated MR's ability to remember left and right features of familiar places from different perspectives, a task introduced by Bisiach and Luzzatti (1978) and subsequently used by several authors (e.g. Halligan et al. 1992). MR's wife described their bedroom as having an arm-chair and a window on one side and a chest of drawers and a door on the other. When asked to draw the plan, MR just schematically indicated the furniture's position. While imaging that he was facing the head of the bed, he erroneously located the arm-chair in the upper right-hand corner of the room instead of the lower left-hand one. Then, while imagining that he was facing the foot of the bed, he failed to indicate the chest of drawers, which from that vantage point was located on the left.
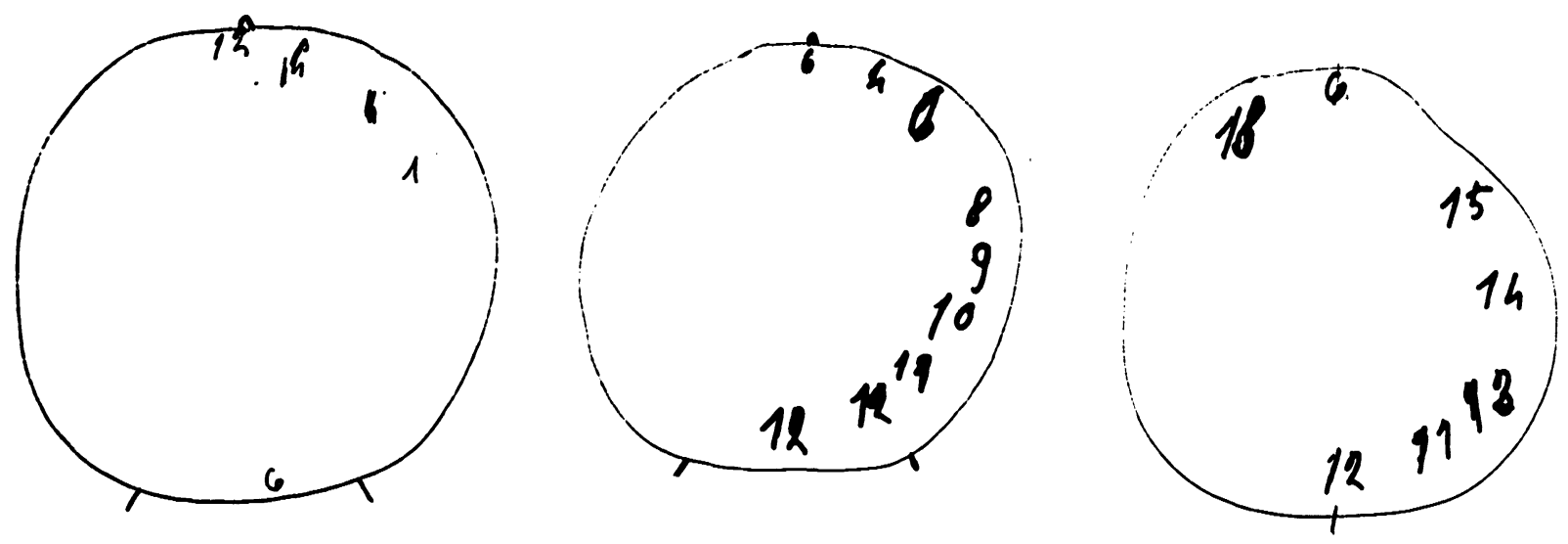

FIG. 4. Clock completion task. 
Position preference. Several of the tasks featured multiple choice displays (Crossing out of digits - Corsi's block tapping test - Raven's Progressive Matrices (PM) - Tactile form perception - Facial recognition Visual form discrimination) which allowed us to detect the answer position. Position preference was defined in terms of an evident difference in the number of responses given in the left or right position (and mid-position when there were three sections) with respect to chance, when the correct choices were balanced across the different regions of the answer display. Position preference was strongly evident in all tasks. We may recall that tests are generally constructed in such a way that correct answers are balanced between the left and right parts of the display. The expected value of position preference in normals is therefore null. Brain damaged patients often show a slight position preference ipsilateral to the hemispheric lesion. The behaviour of MR is reported in detail in Table II.

TABLE II. Position preference assessment: number of choices on the left, middle and right side

\begin{tabular}{llcc}
\hline Task & Left & Middle & Right \\
\hline Visual form discrimination & $3(8)^{1}$ & & $13(8)$ \\
Facial recognition & $4(17)$ & $18(19)$ & $21(18)$ \\
Tactile form perception & $2(3)$ & $4(4)$ & $4(3)$ \\
Digit cancellation test & $0(20)$ & $6(23)$ & $11(17)$ \\
Corsi's block tapping test & $9(36)$ & $54(54)$ & $68(54)$ \\
Raven's progressive matrices & $3(14)$ & $19(20)$ & $26(14)$ \\
\hline
\end{tabular}

${ }^{1}$ Responses expected by chance in parentheses.

\section{Memory tasks}

MR's performance (see Table 1) was pathological on almost every task. However, it is likely that both aphasia and neglect influenced this outcome (on Corsi's block tapping test he tapped 68 right-sided alternatives versus nine left-sided blocks). In fact, his score on the Symbol-digit paired associate learning test, which demands neither verbal nor spatial skills was higher than the average score of the control group. In the light of these considerations we cannot draw any firm conclusions about MR's memory.

\section{Other cognitive functions}

Attention. On the Digit Cancellation test MR achieved a score of 8.5 (cut-off $=31$ ). Besides the position preference effect (see the paragraph above), his performance was extremely slow. Even considering the right third of the display, which should be exempt from inattention, MR crossed out only four of the 17 target digits: on average controls crossed out 15.6 digits.
Non-verbal intelligence. The score of Raven's PM38 was 18 (Cut-off $=15$ ), and lies within normal limits, however a marked position preference effect is evident (see the paragraph above and Table II). This suggests that his non-verbal intelligence was not severely impaired.

Visuo-constructional tasks. On the Constructional Apraxia test and on Figure Recomposition from Fragments, MR scored within the normal range.

Affective language. As the right hemisphere is thought to be dominant for the affective tone of the voice (Ross et al. 1989), we tested the patient's prosody (Table III).

TABLE III. Affective language assessment

\begin{tabular}{lcc}
\hline Test & Patient MR & Controls \\
\hline Prosodic-figure matching & & \\
task & $0 / 12^{1}$ & $3.80(1.10)^{2}$ \\
Prosodic repetition & $7.5 / 36^{1}$ & $19.50(1.57)$ \\
Spontaneous affective & & \\
$\quad$ prosody & Severe loss & Normal \\
Facial emotion naming & $4 / 6$ & $3.6(1.52)$ \\
Facial emotion matching & $13 / 18$ & $10.40(2.79)$ \\
\hline 'Defective performance. & \\
'Standard deviations in parentheses.
\end{tabular}

Comprehension of affective language was assessed by asking him to match six affectively intoned renditions (neutral, happy, sad, angry, surprised, disgusted) to six corresponding face drawings. The test included 12 trials, and one point was given for every correct answer (range 0-12).

Affective language repetition was assessed by asking him to repeat the same six renditions from a standard stimulus-tape "Andiamo da un'altra parte"/"let's go somewhere else". All the renditions were administered twice in random order. Four judges scored each utterance on a $0-3$ point scale, where 0 corresponded to a null prosody and 3 to a perfect prosodic repetition. The overall score was the mean rating of the four judges (range 0-36).

Spontaneous speech prosody was rated by five judges as normal, moderately impaired or severely impaired. The patient's speech was judged as 'severely impaired' by the majority of judges.

In addition, to test his ability to perceive facial emotions, MR was asked to name or describe the emotion depicted in the six drawings of faces used in the previous test (range 0-6), and to match a stimulus photograph with the one representing the same facial emotion in a different subject from four other photographs (courtesy of Luigi Pizzamiglio, unpublished data): six emotions (happiness, sadness, fear, anger, 
surprise, disgust) were shown three times each (range $0-18)$.

In order to check the level of MR's performance, we examined five age and education matched controls, whose means are reported in Table III.

Although MR's performance on processing the facial expression of emotions was normal (naming and name/picture matching), the affective language comprehension, repetition and spontaneous speech were severely impaired. According to Gorelick and Ross (1987) this pattern of deficits could be classified as global aprosodia. Aprosodia following deep rightsided lesions has been reported by Ross et al. (1989). Moreover, two of the fourteen right-hemisphere damaged patients from Gorelick and Ross's (1987) series showed aprosodia after haemorrhage involving the deep structures. The foregoing studies suggest that also the anatomical organisation of affective language includes cortical and subcortical areas. The impairment of MR's affective language indicates that its hemispheric representation was right-sided, thus, not showing a cross-localisation.

\section{CONCLUSION}

MR was impaired on tasks generally demanding both left and right hemispheric competence. On the one hand he presented aphasia with an oral/written dissociation and severe acalculia, while on the other, he demonstrated an impairment of affective language, unilateral neglect and a position preference, all of which are generally observed after right hemisphere damage. Mild unilateral neglect can be observed even in patients with left hemisphere damage (for a discussion see De Renzi, 1982) and, in principle, the main anatomical substrate for attention could have been cross-localised (i.e. left-sided) in MR. In our view however, the features of unilateral neglect and marked position preference exhibited by MR would be better accounted for by a standard (i.e. rightsided) representation of attentional mechanisms. MR still showed unilateral neglect 4 months after his stroke, and this argues most strongly in favour of the severity of the disorder (as opposed to the mild picture generally observed after a standard left-sided lesion). Although we cannot draw any firm conclusions about MR's memory, attention, non-verbal intelligence, spatial cognition or perceptual skills we are inclined to think that none of these functions was definitely impaired per se. Visuo-constructional abilities, ideo-motor and bucco-facial praxis, and colour association were spared.

\section{Acknowledgements}

We are indebted to Dr Orazio Zoccarato for performing the SPECT examination. Gillian Jarvis revised the English version of the paper.

\section{REFERENCES}

Basso A and Capitani E (1979) Un test standardizzato per la diagnosi di acalculia. Descrizione e valori normativi. Ap-Rivista di applicazioni psicologiche, 1, 551-564.

Basso A, Capitani E, Laiacona M and Zanobio ME (1985) Crossed aphasia: one or more syndromes? Cortex, 21, 25-45.

Benton AR, Hamsher K deS, Varney NR and Spreen O (1983) Contributions to Neuropsychological Assessment. A Clinical Manual. New York: Oxford University Press.

Bisiach E and Luzzatti C (1978) Unilateral neglect of the representational space. Cortex, 14, 129-133.

Branch C, Milner B and Rasmussen T (1965) Intracarotid sodium amytal for the localization of cerebral dominance. Journal of Neurosurgery, 21, 399-405.

Capitani E and Laiacona M (1988) Aging and psychometric diagnosis of intellective impairment: some considerations on tests scores and their use. Developmental Neuropsychology, 4, 325-330.

Capitani E, Laiacona M, Ciceri E and Gruppo Italiano per lo Studio Neuropsicologico dell'Invecchiamento (1991) Sex differences in spatial memory: a reanalysis of block tapping long-term memory according to the short-term memory level. Italian Journal of Neurological Sciences, 12, 461-466.

Cappa SF and Vignolo LA (1979) 'Transcortical' features of aphasia following left talamic hemorrage. Cortex, 15, 121-130.

Démonet JF, Celsis P, Puel M, Cardebat D, Marc-Vergnes JP and Rascol A (1992) Thalamic and non-thalamic subcortical aphasia: a neuroloinguistic and SPECT approach. In: Neuropsychological Disorders Associated with Subcortical Lesions. (Eds SF Cappa, G Vallar and KW Wallesh), pp.397-411. Cambridge, Cambridge University Press.

De Renzi E (1982) Disorders of Space Exploration and Cognition, pp.90-95, Chichester, J. Wiley \& Sons.

De Renzi E, Pieczuro A and Vignolo LA (1966) Oral apraxia and aphasia. Cortex, 2, 50-73.

De Renzi E, Pieczuro A and Vignolo LA (1968) Ideational apraxia: a quantitative study. Neuropsychologia, 6, 41-52.

De Renzi E, Motti F and Nichelli P (1980) Imitating gestures: a quantitative approach to ideomotor apraxia. Archives of Neurology, 37, 6-10.

De Renzi E, Faglioni P and Sorgato P (1982) Modality-specific and supramodal mechanisms of apraxia. Brain, 105, 301-312.

Fisher RS, Alexander MP, Gabriel C, Gould E and Milione J (1991) Reversed lateralisation of cognitive functions in right handers. Exceptions to classical aphasiology. Brain, 114, 245-261.

Gloning K (1977) Handedness and aphasia. Neuropsychologia, 15, 355-358.

Gorelick PB and Ross ED (1987) The aprosodias: further functional-anatomical evidence for the organization of 
affective language in the right hemisphere. Journal of Neurology, Neurosurgery, and Psychiatry, 50, 553-560.

Halligan PW, Marshall JC and Wade DT (1992) Contrapositioning in a case of visual neglect. Neuropsychological Rehabilitation, 2, 125-135.

Hécaen H, Mazars G, Ramier AM, Goldblum MC and Merienne L (1971) Aphasie croisée chez un droitier bilingue (vietnamien-français). Revue Neurologique, 124, 319-323.

Joanette Y, Puel M, Nespoulous JL, Rascol A and Lecours AR (1982) Aphasie croisée chez les droitiers. I. Revue de la littérature. Revue Neurologique, 138, 575-586.

Luzzatti C, Willmes K and DeBleser R (1991) Aachener Aphasie Test (A.A.T.): Versione italiana. Firenze, Organizzazioni Speciali.

Manning L, Halligan PW and Marshall JC (1990) Individual variation in line bisection: a study of normal subjects with application to the interpretation of visual neglect. Neuropsychologia , 28, 647-655.

Novelli G, Papagno C, Capitani E, Laiacona M, Vallar G and Cappa SF (1986) Tre test clinici di memoria verbale a lungo termine. Taratura su soggetti normali. Archivio di Psicologia, Neurologia e Psichiartia, 2, 278-296.

Oldfield RC (1971) The assessment and the analysis of handedness: the Edinburgh Inventory. Neuropsychologia, 9, 97-113.
Orsini A, Grossi D, Capitani E, Laiacona M, Papagno C and Vallar G (1987) Verbal and spatial immediate memory span: normative data from 1355 adults and 1112 children. Italian Journal of Neurological Sciences, 8, 539-548.

Pillon B, Desi M and Lhermitte F (1979) Deux case d'aphasie croisée avec jargonagraphie chez des droitiers. Revue Neurologique, 135, 15-30.

Puel M, Démonet JF, Cardebat D, Berry I, Celsis P, MarcVergnes JP and Rascol A (1992) Three topographical types of thalamic aphasia: a neurolinguistic, MRI, and SPECT study. In: Neuropsychological Disorders Associated with Subcortical Lesions. (Eds SF Cappa, G Vallar and KW Wallesh), pp.411-426. Cambridge University Press, Cambridge.

Ross ED, Anderson B and Morgan-Fisher A (1989) Crossed aprosodia in strongly dextral patients. Archives of Neurology, 46, 206-209.

Salmaso D and Longoni AM (1985) Problems in the assessment of hand preference. Cortex, 21, 533-549.

Spinnler H and Tognoni G (1987) Standardizzazione e taratura italiana di test neuropsicologici. Italian Journal of Neurological Sciences, 6 (Suppl. 8).

Zangwill OL (1979) Two cases of crossed aphasia in dextrals. Neuropsychologia, 17, 167-172.

\section{APPENDIX}

Some examples of spontaneous speech and oral picture naming

Spontaneous speech

\begin{tabular}{|c|c|}
\hline Examiner & Patient MR \\
\hline 'Come mai si trova qui?' & 'Si, si trovo qui' \\
\hline & (yes, are you here) \\
\hline 'Cos'è?' & 'E' la... la...' \\
\hline (What is that?) & (It is the ... the ...) \\
\hline 'Che lavoro faceva?' & $\begin{array}{l}\text { 'Facevo un } \ldots \text { un ... no' } \\
\text { (It was a ... a ... no) }\end{array}$ \\
\hline 'What was your job?) & $\begin{array}{l}\text { (tt was a ... a ... no) } \\
\text { 'Disturbi sono quelli ... a ... a bo ...' }\end{array}$ \\
\hline (What are your disturbances?) & (Disturbances are those ... a ... a bo ...) \\
\hline 'Che cosa si è sentito' & $\begin{array}{l}\text { 'Sono sono .. esta ... fatto fatto ... una ... una ... spo ... } \\
\text { ostia' }\end{array}$ \\
\hline (What did you feel?) & (I am, am ... esta ... done ... done.. a ... a a... spo ... ostia) \\
\hline $\begin{array}{l}\text { 'Che cosa usa per farsi la barba?' } \\
\text { (What do you use for shaving?) }\end{array}$ & $\begin{array}{l}\text { 'Prendo, prendo due palà ... due perari...' } \\
\text { (I keep keep two palà... two perari...) }\end{array}$ \\
\hline \multicolumn{2}{|l|}{ Oral picture naming } \\
\hline Stimulus & Answer \\
\hline occhiali (glasses) & lampadario (light) \\
\hline stanghetta (side of glasses) & coperchio (cover) \\
\hline pipa (pipe) & matita (pencil) \\
\hline borsa (bag) & secchio (bucket) \\
\hline lampada (lamp) & lampione (street-lamp) \\
\hline
\end{tabular}




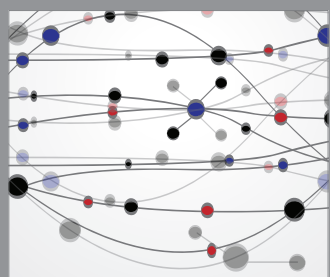

The Scientific World Journal
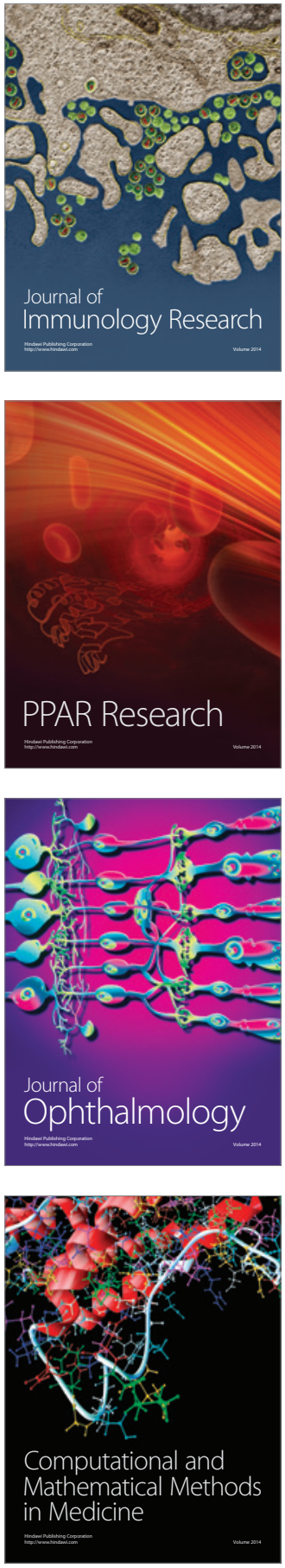

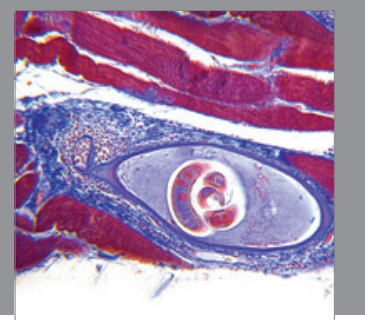

Gastroenterology

Research and Practice
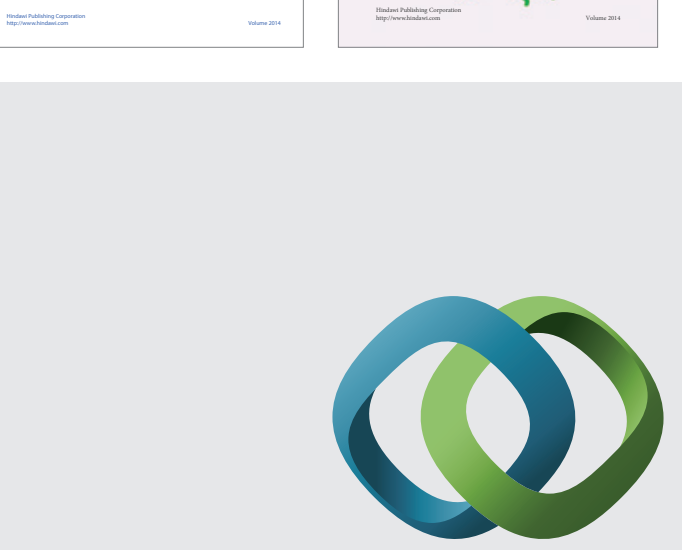

\section{Hindawi}

Submit your manuscripts at

http://www.hindawi.com
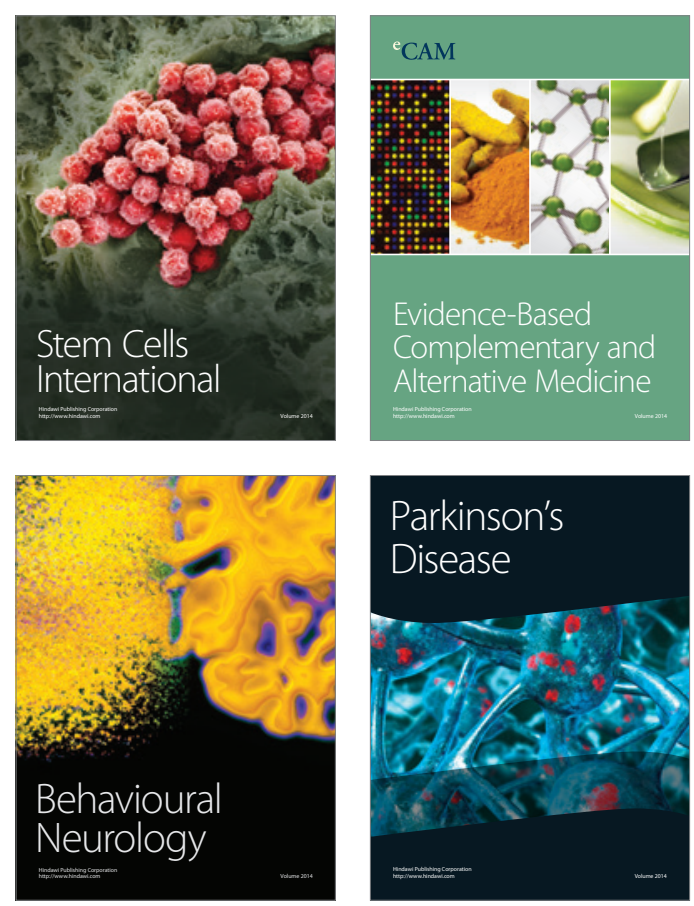

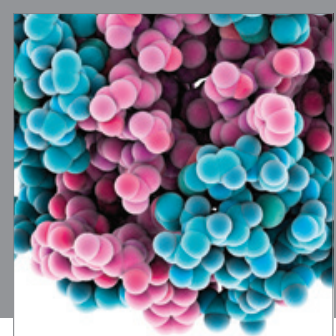

Journal of
Diabetes Research

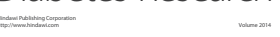

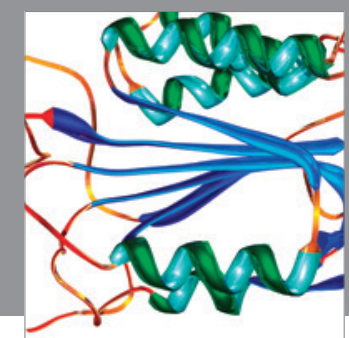

Disease Markers
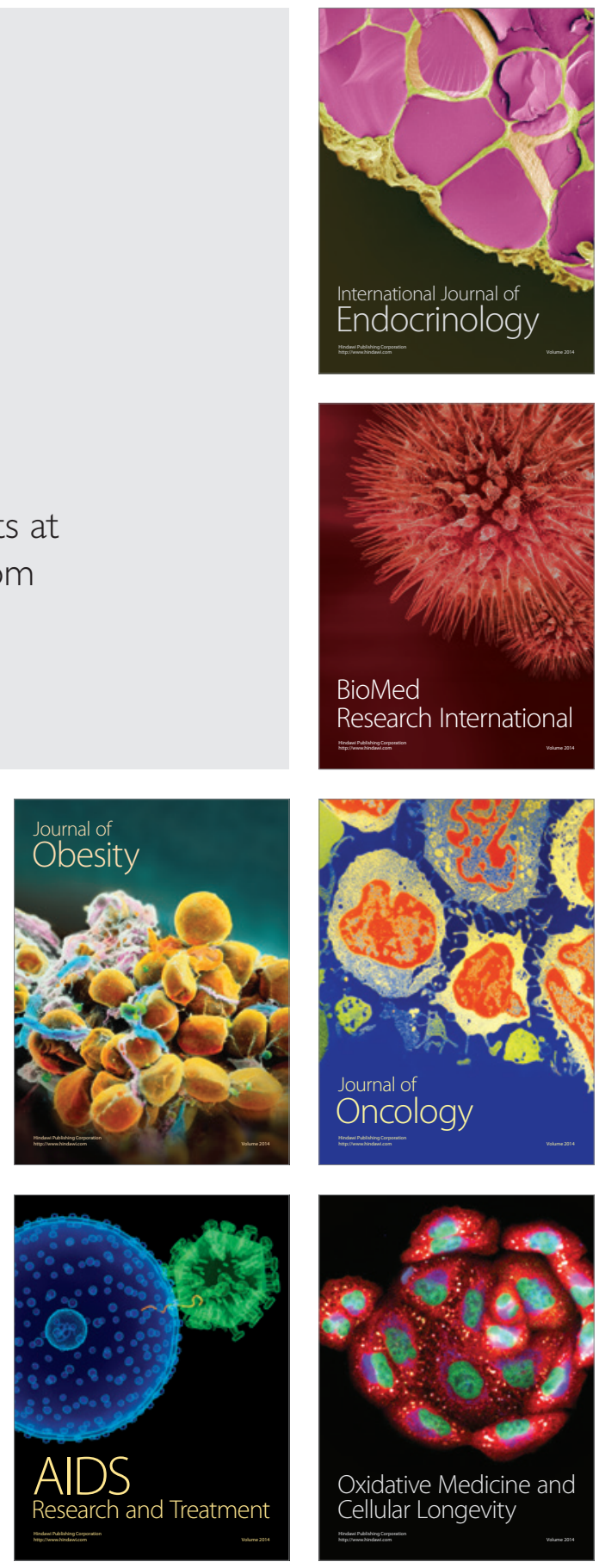